\title{
EFFECTS OF DROUGHT STRESS ON GROWTH AND ACCUMULATION OF PROLINE IN FIVE RICE VARIETIES (ORYZA SATIVA L.)
}

\author{
SHUKANTA SAHA*, HASNA HENA BEGUM AND SHAMIMA NASRIN \\ Department of Botany, Jagannath University, Dhaka-1100, Bangladesh
}

\begin{abstract}
A pot experiment was conducted to study the effect of drought stress on growth and accumulation of proline in five rice varieties namely BRRI dhan-30, BRRI dhan-32, BRRI dhan-34, BRRI dhan-38 and BRRI dhan-56 and to characterize them on the basis of their behavior of drought tolerance. Drought stress caused the decrease of growth like root length, shoot length, root fresh weight, shoot fresh weight, root dry weight, shoot dry weight, the ratio of root-shoot length. Among the rice varieties, BRRI dhan-56 showed the lowest decrease of growth of plant. BRRI dhan-56 showed the least decrease of water content in both root and shoot. On the other hand, the accumulation of proline was increased in five rice varieties under stress. BRRI dhan-56 showed the highest (3.7folds) increase in the accumulation of proline in leaf under stress. This study suggests that BRRI dhan-56 may possess drought tolerance characteristics while BRRI dhan-30, BRRI dhan-32, BRRI dhan-34 and BRRI dhan-38 may be drought sensitive based on their growth and proline accumulation behavior.
\end{abstract}

Key words: Drought stress, Growth, Water content, Proline accumulation, Rice

\section{Introduction}

Several environmental factors drastically affect plant growth development and yield performance of most crops (Bashan 1998). Drought, one of the environmental stresses, is the most significant factor restricting plant growth and crop productivity in the majority of agricultural fields of the world (Tas and Tas 2007).

Rice (Oryza sativa L.) is one of the most widely consumed cereal crops, providing a staple diet for almost half of the world's population (Song et al. 2003). More than $90 \%$ of the world's rice is grown and consumed in Asia, where rice is cultivated on 135 million ha with an annual production of 516 million tonnes (Roy and Misra 2002). It is estimated that about $50 \%$ of the world rice production is affected more or less by drought (Bouman et al. 2005). Reduction of plant growth is the most typical symptom of drought stress (Sairam and Srivastava 2001). It reduces plant growth by affecting various physiological and biochemical processes, such as photosynthesis, respiration, translocation, ion uptake, carbohydrates, nutrient metabolism and growth promoters (Farooq et al. 2008, Jaleel et al. 2008 and Razmjoo et al. 2008). Production and accumulation of free amino acids, especially proline by plant tissue during drought is an adaptive response. Thus proline can be used as a metabolic marker in relation to stress

\footnotetext{
*Author for correspondence: <sahashukanta@gmail.com, saha.s@bot.jnu.ac.bd>
} 
(Caballero et al. 2005). Plant tolerance to unfavourable conditions, particularly water deficit, has been associated with proline (a non-protein amino acid formed in the leaf tissues of plants exposed to water stress) accumulation (Ashraf and Foolad 2007).

The aim of this work was to study the effects of drought stress on growth and proline accumulation of five rice varieties and to characterize their behavior on the basis of drought tolerance.

\section{Materials and Methods}

A pot experiment was carried out at the research garden of the Department of Botany, Jagannath University, Dhaka. Seeds of five rice varieties viz., BRRI dhan-30, BRRI dhan-32, BRRI dhan-34, BRRI dhan-38 and BRRI dhan-56 had been collected from Bangladesh Rice Research Institute (BRRI), Gazipur. Half loamy soil and half compost soil were used by mixing. The pot experiment was set up in net house of the research garden.

The seeds were surface sterilized by agitation in $95 \%$ ethanol for $1 \mathrm{~min}$ followed by five washings with sterile water. Seeds were rinsed in distilled water for about 30 minutes. These seeds were allowed to germinate on a filter paper in Petri dishes, moistened with 4 $\mathrm{ml}$ of distilled water. The Petri dishes were arranged randomly and stored at room temperature $\left(24 \pm 2^{\circ} \mathrm{C}\right)$ under dark conditions. The Petri dishes were covered to prevent the loss of moisture by evaporation under laboratory condition. Within three days the seeds germinated from the date of sowing. Drought stress was imposed by withholding irrigation at 21 days after sowing in 25 pots. Water level in well-watered treatment (control) was maintained at $5 \mathrm{~cm}$ above the surface of the soil in the rest 25 pots. The experiment was arranged with CRD with five replications. Plants were collected at 10 days after stress. After taking fresh weight the root and shoot were dried in an oven for 72 hours at $80^{\circ} \mathrm{C}$ to a constant weight. Several growth parameters like root and shoot length, length of root/shoot ratio, fresh weight and dry weight of shoot and root were measured. Water contents of root and shoot were determined. Proline accumulation of leaves for each treatment was determined at 16 days after stress following the method of Bates et al. (1973).

\section{Results and Discussion}

Drought stress decreased the length of root in BRRI dhan-30, BRRI dhan-32, BRRI dhan-34, BRRI dhan-38 and BRRI dhan-56 by 45.71, 41.94, 33.73, 31.59 and 23.98\%, respectively at 10 days of treatment whereas BRRI Dhan-56 showed the least decrease of root length under stress (Fig. 1). Root length is an important trait of plant varieties in the 
drought stress condition and roots play an important role in plant survival during periods of drought (Hoogenboom et al. 1987). In general, variety with longer root growth has resistance ability to drought condition (Leishman and Westoby 1994). It decreased the length of shoot by $30.69,16.63,22.13,15.89$ and $8.22 \%$, respectively at 10 days of treatment and BRRI Dhan-56 showed the least decrease of shoot length under stress (Fig. 2). The results are in agreement with Khan et al. (2001) who found drought stress decreased the plant height in maize.
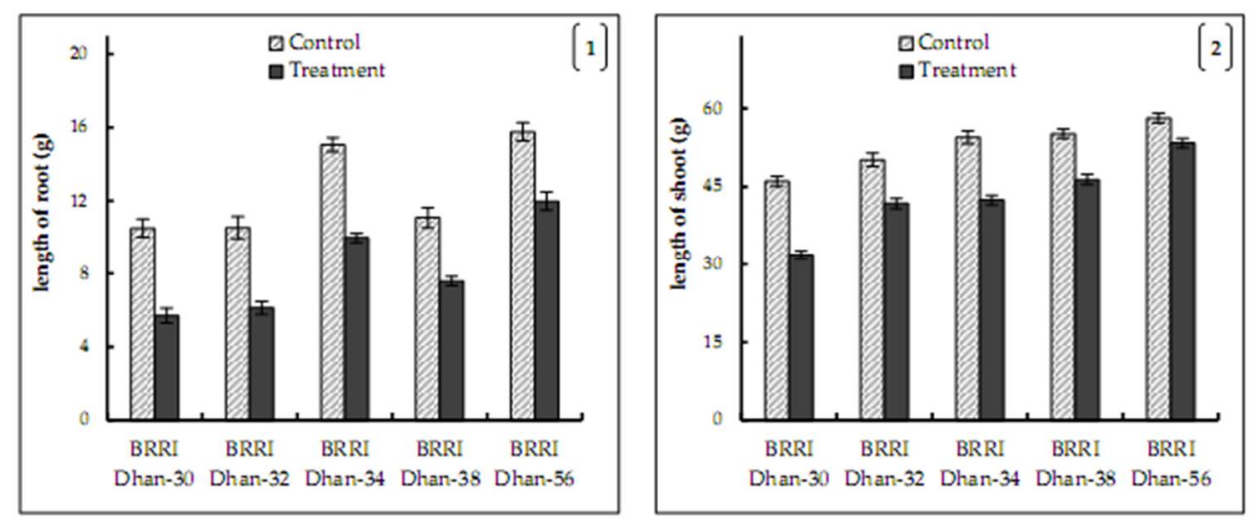

Figs 1-2: (1) The effect of drought stress on the length of root in rice. The bars represent \pm standard error. (2) The effect of drought stress on the length of shoot in rice.

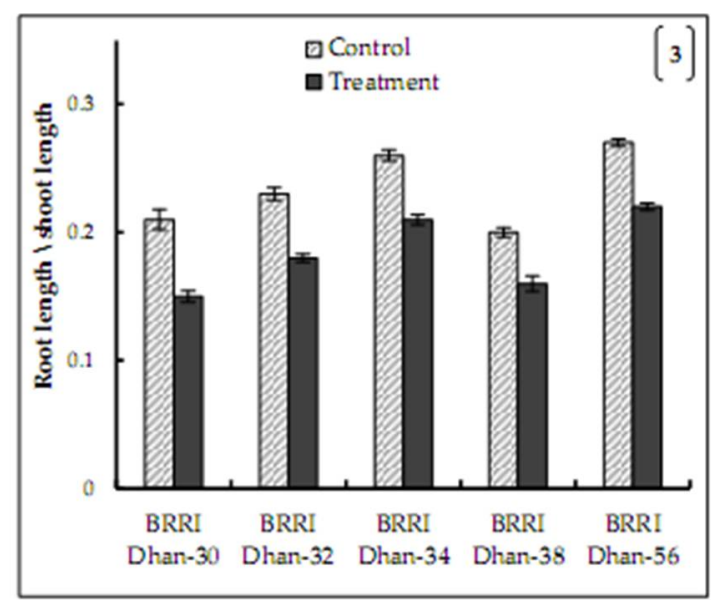

Fig. 3. The effect of drought stress on the length of root-shoot ratio in rice. 

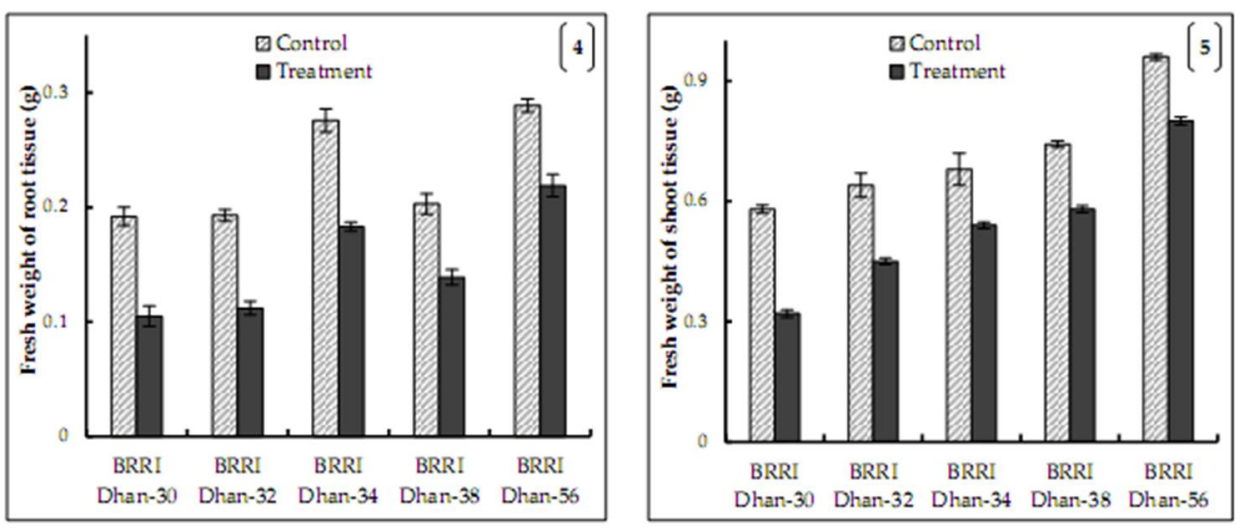

Figs 4-5. (4) The effect of drought stress on fresh weight of root tissue in rice. (5) The effect of drought stress on fresh weight of shoot tissue in rice.

The ratio of root-shoot length decreased by $28.57,21.74,19.23,20$ and $18.52 \%$ in BRRI dhan-30, BRRI dhan-32, BRRI dhan-34, BRRI dhan-38 and BRRI dhan-56, respectively whereas BRRI Dhan-56 showed the least decrease of the length of root: shoot under stress (Fig. 3). Similarly, Alvareza et al. (2009) showed the decrease of the root/shoot length ratio in carnation plants as respond to drought. The fresh weight of root at 10 days of treatment was decreased by $24.22-45.31 \%$. The minimum and maximum decreases were found in BRRI dhan-56 and BRRI dhan-30, respectively (Fig. 4). It decreased fresh weight of shoot in all the varieties and the range of decrease was $16.67-44.83 \%$. Among five rice varieties, BRRI Dhan-56 showed the least decrease of shoot fresh weight under stress (Fig. 5). The dry weight of root and shoot also decreased at 10 days of treatment. The decreases were $38.09-64.71 \%$ in case of root (Fig. 6) and $21.57-47.31 \%$ in shoot (Fig. 7). BRRI dhan-56 showed the lowest decrease in root and shoot dry weight followed by BRRI dhan-38, BRRI dhan-34, BRRI dhan-32 and BRRI dhan-30. Similar results about reduction in the shoot weight were reported by Mohammadian et al. (2005) in suger beet. Lum et al. (2014) reported the significant reduction in dry matter of different organs as compared to control in rice varieties under water stress.

Drought stress decreased water content of root by 43.43, 39.77, 28.37, 25 and 20.35\% in BRRI dhan-30, BRRI dhan-32, BRRI dhan-34, BRRI dhan-38 and BRRI dhan-56, respectively at 10 days of treatment whereas BRRI Dhan-56 showed the least decrease of root water content under stress (Fig. 8). Results revealed that decreases in water content of shoot had similar trend as obtained in decrease in water content of root and the range varied from $15.74-44.35 \%$. Among the rice varieties, BRRI Dhan-56 showed the lowest decrease of shoot water content under stress (Fig. 9). Similarly, Hossain et al. (2016) showed root and shoot water contents decreased under water stress condition. 

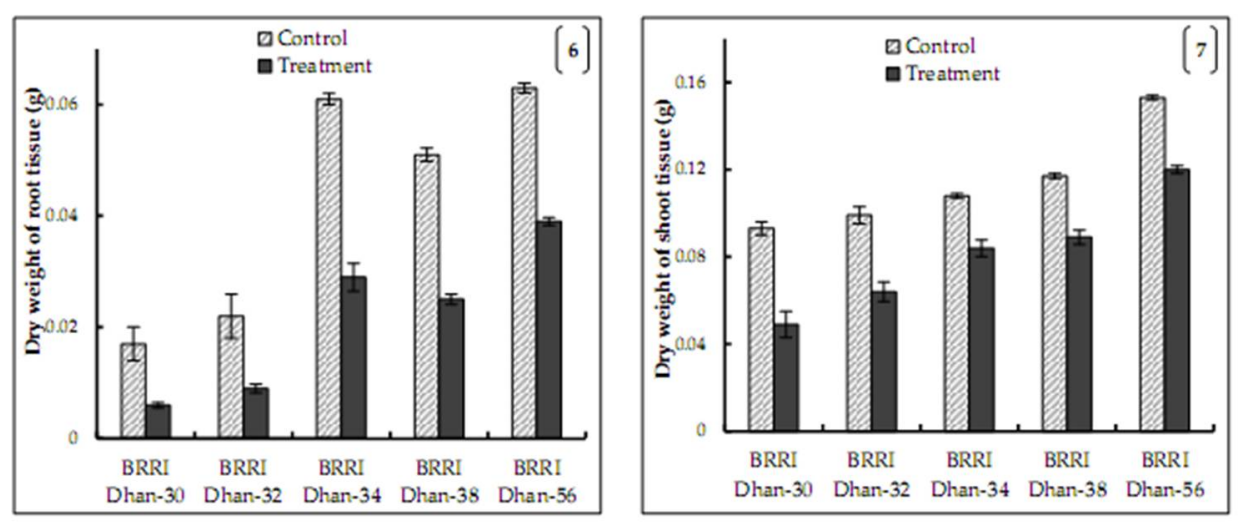

Figs 6-7. (6) The effect of drought stress on dry weight of root tissue in rice. (7) The effect of drought stress on dry weight of shoot tissue in rice.
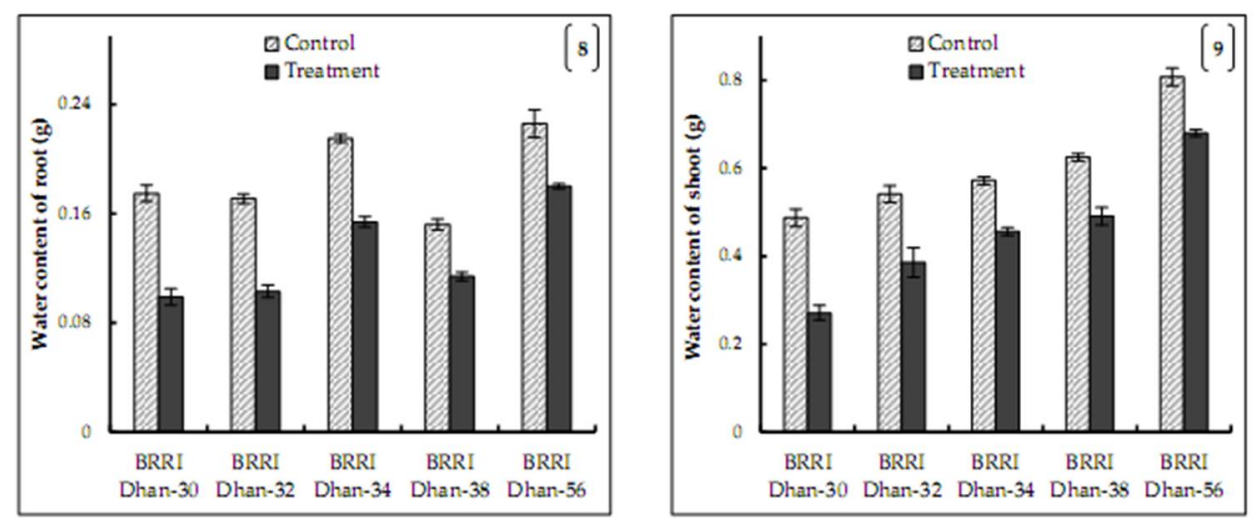

Figs 8-9. (8) The effect of drought stress on water content of root in rice. (9) The effect of drought stress on water content of shoot in rice.

Drought stress increased proline accumulation in the leaf by $56.14,85.1 \%, 1.4-, 1.1-$ and 3.7-folds in BRRI dhan-30, BRRI dhan-32, BRRI dhan-34, BRRI dhan-38 and BRRI dhan-56, respectively at 16 days of treatment. BRRI dhan-56 showed the highest increase in the accumulation of proline followed by BRRI dhan-34, BRRI dhan-38, BRRI dhan-32 and BRRI dhan-30 (Fig. 10). Similarly, drought stress increased the accumulation of proline in groundnut varieties (Ranganayakulu 2015) and in chickpea (Mafakheri et al. 2010). The increase in proline level may help to maintain osmotic potential of cytoplasm of cells which is important for survival of plants under stress (Saha et al. 2016). Accumulation of proline has been advocated as a parameter of selection for stress tolerance (Jaleel et al. 2007). 


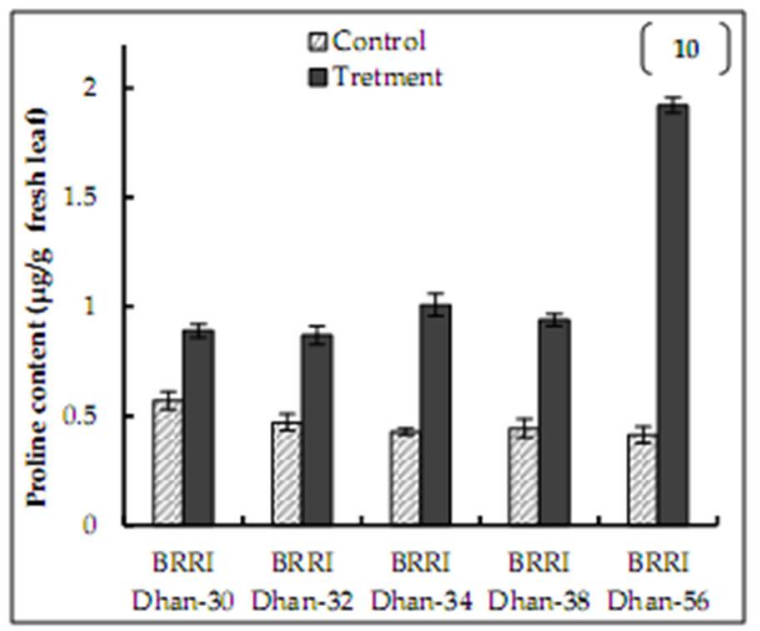

Fig. 10. The effect of drought stress on the accumulation of proline in the leaf of rice.

This study suggests that BRRI dhan-56 variety may possess drought tolerance characteristics while BRRI dhan-30, BRRI dhan-32, BRRI dhan-34 and BRRI dhan-38 varieties may be drought sensitive on the basis of their growth and proline accumulation.

\section{References}

Alvareza, S., A. Navarroa, S. Banon and M. J. Sanchez-Blanco. 2009. Regulated deficit irrigation in potted Dianthus plants: Effects of severe and moderate water stress on growth and physiological responses. Scientia Horticulturae 122: 579-585.

Ashraf, M. and M. R. Foolad. 2007. Roles of glycine betaine and proline in improving plant abiotic stress resistance. Environmental and Experimental Botany. 59(2): 206-216.

Bashan, Y. 1998. Inoculants of plant growth-promoting bacteria for use in agriculture. Biotechnology Advances 16(4): 729-770.

Bates, L., R. P. Waldren and I. D. Teare. 1973. Rapid determination of free proline for water-stress studies. Plant and Soil 39: 205-207.

Bouman, B. A. M., S. Peng, A. R. Castaoeda and R. M. Visperas. 2005. Yield and water use of irrigated tropical aerobic rice systems. Agricultural Water Management 74(2): 87-105.

Caballero, J. I., C. V. Verduzco, J. Galan and E. S. D. Jimenez. 2005. Proline accumulation as a symptom of drought stress in maize: A tissue differentiation requirement. J. Expt. Bot. 39(7): 889-897.

Farooq, M., T. Aziz, S. M. A. Basra, M. A. Cheema and H. Rehamn. 2008. Chilling tolerance in hybrid maize induced by seed priming with salicylic acid. J. Agron. Crop Sci. 194: 161-168.

Hoogenboom, G., M.G. Huck and C. M. Peterson. 1987. Root growth rate of soybean as affected by drought stress. Agron J. 79: 607-614.

Hossain, M. Z., I. U. Rasel and R. Samad. 2016. Soil moisture effects on the growth of lentil (Lens culinaris Medik.) varieties in Bangladesh. Mol.16: 30-40. 
Jaleel, C. A., R. Gopi, B. Sankar, M. Gomathinayagam and R. Panneerselvam. 2008. Differential responses in water use efficiency in two varieties of Catharanthus roseus under drought stress. Comp. Rend. Biol. 331: 42-47.

Jaleel, C. A., R. Gopi, B. Sankar, P. Manivannan, A. Kishorekumar, R. Sridharan and R. Panneerselvam. 2007. Studies on germination, seedling vigour, lipid peroxidation and proline metabolism in Catharanthusroseus seedlings under salt stress. South Afr. J. Bot. 73: 190-195.

Khan, M. B., N. Hussain and M. Iqbal. 2001. Effect of water stress on growth and yield components of maize variety YHS 202. J. Res. Science 12: 15-18.

Leishman, M.R. and M.Westoby. 1994. The role of seed size in seedling establishment in dry soil conditions -experimental evidence from semi-arid species. J. Ecol. 82(2): 249-258.

Lum, M. S., M. M. Hanafi, Y. M. Rafii and A. S. N. Akmar. 2014. Effect of drought stress on growth, proline and antioxidant enzymes of upland rice. J. Anim. Plant Sci. 24(5): 14871493.

Mafakheri, A., A. Siosemardeh, B. Bahramnejad, P.C. Struik and Y. Sohrabi. 2010. Effect of drought stress on yield, proline and chlorophyll contents in three chickpea cultivars. Australian J. Crop Sci. 4: 580-585.

Mohammadian, R., M. Moghaddam, H. Rahimian and S. Y. Sadeghian. 2005. Effect of early season drought stress on growth characteristics of sugar beet genotypes. Turkisk J. Bot. 29: 357-368.

Ranganayakulu, G. S., C. Sudhakar and S. P. Reddy. 2015. Effect of water stress on proline metabolism and leaf relative water content in two high yielding genotypes of groundnut (Arachis hypogaea L.) with contrasting drought tolerance. J. Expt. Bio. Agri. Sciences. 3(1): 2320-8694.

Razmjoo, K., P. Heydarizadeh and M. R. Sabzalian. 2008. Effect of salinity and drought stresses on growth parameters and essential oil content of Matricaria chamomile. Int. J. Agric. Biol. 10: 451-454.

Roy, R. N. and R. V. Misra. 2002. Economic and Environmental Impact of Improved Nitrogen Management in Asian Rice-Farming Systems. Proceedings of the 20th Session of the International Rice Commission 23-26 pp.

Saha, S., R. Samad, P. Rashid and J.L. Karmoker. 2016. Effects of sulphur deficiency on growth, sugars, proline and chlorophyll content in mungbean (Vigna radiata L. var. BARI MUNG-6). Bangladesh J. Bot.45: 405-410.

Sairam, R. K. and G. C. Srivastava. 2001. Water stress tolerance of wheat (Triticum aestivum L.): variations in hydrogen peroxide accumulation and antioxidant activity in tolerant and susceptible genotypes. J. Agron. Crop Sci. 186: 63-70.

Song, Z. P., B. R. Lu, Y. G. Zhung and J. K. Chen. 2003. Gene flow from cultivated rice to the wild species Oryza rufipogon under experimental field conditions. New Phytologist. 157(3): 657-665.

Tas, S. and B. Tas. 2007. Some physiological responses of drought stress in wheat genotypes with different ploidity in Turkiye. World J. Agri. Sciences 3: 178-183. 